\title{
Core and activity-specific functional participatory roles in collaborative science learning
}

\author{
Olli-Pekka Heinimäki ${ }^{a}$, Simone Volet ${ }^{b}$, Marja Vauras ${ }^{a}$
}

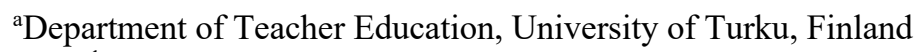

${ }^{\mathrm{b} S c h o o l ~ o f ~ E d u c a t i o n, ~ M u r d o c h ~ U n i v e r s i t y, ~ A u s t r a l i a ~}$

Article received 26 March 2019 / Article revised 6 September / Accepted 9 March 2020 / Available online 21 April

\begin{abstract}
Prior research on the significance of roles in collaborative learning has explored their impact when they are pre-assigned to group members. In this article, it is argued that focusing on assigned roles downplays the spontaneous, emergent, and interactional nature of roles in small task groups and that this focus has limited the development of generalizable frameworks aimed at understanding the impact of roles in and across collaborative learning settings. A case is built for the importance of focusing on the functional participatory roles enacted during collaborative learning and for conceptualising these roles as emergent, dynamic, and evolving in situ (first claim). Further, a flexible conceptual framework for the analysis and understanding of such roles across diverse collaborative science-learning activities is proposed, based on the assumption that during collaborative learning, both core and activity-specific roles are enacted (second claim). The core roles resemble each other across activities as they associate closely with the nature of the science discipline itself, whereas the activity-specific roles vary across activities as their emergence is dependent on the affordances, demands, and characteristics of the particular activity and environment. Data from three diverse science-learning environments, including four totally or partly student-led collaborative science activities, were scrutinized to establish the degree of empirical support for this assumption and, thereby, the conceptual usefulness of the proposed framework. The contributions of the framework for future research of collaborative science learning are discussed.
\end{abstract}

Keywords: roles; collaborative learning; process-data analysis; situative approach; science learning 


\section{Introduction}

Totally or partly student-led (referred to simply as student-led hereafter) collaborative learning activities are increasingly in use across educational levels and disciplines. In science classrooms, such activities aim to stimulate students' deep learning and engagement through co-construction of science knowledge with peers (Ucan \& Webb, 2015; Webb, 2008). Student-led collaborative learning activities are often characterized by their informal and open-ended nature (Volet, Summers, \& Thurman, 2009), and recent research has emphasized the emergent, interactive and dynamic nature of group processes as they unfold during such activities (e.g., Hadwin, Järvelä, \& Miller, 2018; Hilpert \& Marchand, 2018). The inherently dynamic nature of collaborative learning forms an integral part of the situative perspective (Greeno, 1998, 2006), which is concerned by the complex activity systems constituted by individual cognitive agents interacting with each other and with their environment (including tools, technological artefacts, tasks, communities, etc.). Studies grounded in this perspective have explored how individuals and context operate jointly to produce outcomes in situ (Turner \& Nolen, 2015).

As students interact with each other, the task and the learning context, they constantly enact roles that are expected to have a major impact on the success of the collaboration. The importance of roles in collaborative groups has long been recognised, as educational research examining the benefits of pre-assigning desirable roles to group members goes back several decades (e.g., Johnson \& Johnson, 1989; Slavin, 1996). This line of research has re-gained momentum in recent computer-supported collaborative learning (CSCL) research (e.g., Strijbos, Martens, Jochems, \& Broers, 2004; Gu, Shao, Guo, $\& \mathrm{Lim}, 2015)$. However, although roles are recognised as fundamental in group dynamics and for effective group work (Forsyth, 2014), prior research in educational settings has tended to concentrate on the roles that are pre-assigned and scripted for students. As a consequence, an understanding of the roles that emerge spontaneously and are enacted dynamically in situ during student-led collaborative activities is still lacking. In light of the increased importance of collaborative groups in educational settings and teams in the workplace, this gap needs to be addressed.

Such research requires methodologies that capture and analyse "learners-in-the-context" (Nolen, Horn, \& Ward, 2015, p. 237). The insight gained from the fragmented line of research on roles, conceptualised as emergent and dynamic (e.g., Volet, Vauras, Salo, \& Khosa, 2017; Lehmann-Willenbrock, Beck, \& Kauffeld, 2016; Sarmiento \& Shumar, 2010), has enhanced our understanding of reallife collaborative learning but this is not without methodological challenges. One challenge originates from the fact that empirical studies on the dynamics of collaborative learning groups (not unlike other research fields) have involved the constant development of new coding systems or the revision of existing ones, aimed at capturing the specific behaviours and interactions assumed to be influenced by the characteristics of the particular situation being studied (Volet \& Summers, 2013). Even though a datadriven approach is much needed to complement a theory-driven one, this raises challenges for comparing findings obtained across multiple settings, activities and groups. As a consequence, the development of more generalizable coding systems has been complicated (Nolen et al., 2015; Turner \& Nolen, 2015; Volet \& Summers, 2013). As argued by Volet and Summers, there is a pressing need to develop coding systems that are both sensitive enough to capture the specific characteristics of the data in question and general enough to address scaling issues.

To address the conceptual gaps in prior research on roles (see Strijbos \& Laat, 2010), a flexible conceptual framework for understanding and analysing emergent task-related functional participatory roles in and across collaborative science-learning activities is tentatively proposed. This framework acknowledges that functional participatory roles are emergent, spontaneously enacted during collaborative learning activities as well as dynamic and evolving in situ (first claim). It also assumes that both core and activity-specific roles are enacted by students during collaborative science learning (second claim). To provide some validation for the proposed framework and address the methodological challenge related to generalisation of the findings, data from three distinct science-learning environments are presented and scrutinized to explore the extent of empirical support for the assumption of core and activity-specific functional participatory roles enacted during collaborative science learning. 
To build the conceptual case for the two claims, the next section reviews in turn the variety of role typologies and frameworks in the literature, and the range of empirical studies on roles in collaborative learning research.

\subsection{Variety of role typologies and frameworks}

It is easy to agree with Moxnes (1999) that "[i]n research of small groups ... an extraordinary range of roles have been suggested" (p. 110) as one can find a large repertoire of role typologies and frameworks in the extant small-group literature. However, no generally endorsed typology or framework exists (Stewart, Fulmer, \& Barrick, 2005). Therefore, there is still a call for the establishment of role frameworks, typologies, and coding systems to enhance our understanding and facilitate the analysis of roles in different small-group contexts, such as collaborative learning groups.

The majority of prior work in the field has been conducted in work-related contexts and with different type of small task groups. Pioneering work, from which many studies have drawn since across disciplines, consists of Benne and Sheats' (1948, reprinted 2007) typology of functional roles of group members, which identifies as many as 27 distinct roles (e.g., information giver, procedural technician, follower), and the work of Bales (1951; see also Bales \& Slater, 1955), who classified group members roles into two distinct foci (i.e., task-specialist and socio-emotional specialist). One subsequent and well-known typology is the classification of team roles (e.g., team worker, coordinator, implementer) by Belbin (e.g., 1993), who argued that high-performing teams need a balanced mix of different roles to be represented in the team. Later, with a typology of productive roles (e.g., supporter, proposer, recorder), Chiu (2000) linked roles with three strategic behavioural dimensions that an individual can apply in social interaction: i) evaluation of previous action (supportive, critical, unresponsive), ii) knowledge content (contribution, repetition, null), and iii) invitational form (command, question, statement). Chiu's framework has provided helpful grounding for empirical investigations into how individual actions, and the quality of such actions, interact dynamically with the actions of other group members when the group is working toward a joint goal (Volet et al., 2017). To sum up, research to date has identified two broader types of roles in task groups: task and socio-emotional roles (Driskell, Driskell, Burke, \& Salas, 2017; Forsyth, 2014). The framework proposed in this article focuses on task-related roles (i.e., roles relating to the work of the group toward task achievement), notwithstanding that socioemotional roles are expected to influence the enactment of task-related roles and, in turn, the quality of task achievement.

Because of this extant multiplicity of typologies and frameworks, Driskell et al. (2017) aimed recently to trace core team roles by integrating existing role typologies of work teams. This endeavour was based on the findings of another study (see Gregory, Shimone, Burke, \& Salas, 2015) in which, according to Driskell et al. (2017), 23 unique team-role typologies were discovered in a pool of 139 research papers via a comprehensive literature review, yielding the identification of 164 distinct roles. Even though some of the variations turned out to be terminology-based (similar roles had been labelled differently), roles unique to certain team-role contexts were also identified. As the bulk of these reviewed typologies covered roles in work-related contexts (Driskell et al., 2017), no straightforward generalizations can be drawn to collaborative learning contexts. However, these findings offer hypothetical grounding to assume that there may be core roles underpinning collaborative science learning, but also roles that are more specific for certain science learning activities.

\subsection{Roles in collaborative learning research}

While the main aim of research on roles in work-related contexts has been to identify roles that are crucial for organizations and teams, and to explore individual preferences and abilities to take over those roles (e.g., Belbin, 1993), collaborative learning research has taken a different approach on the study of roles by focusing mainly on pre-assigned and scripted roles. Pre-determined roles for learners have long been suggested as a valuable way to improve the quality of collaboration and group performance because they foster productive individual inputs and more equal participation in collaborative 
task completion (e.g., Cohen, 1994; Johnson \& Johnson, 1989; Slavin, 1996). More recently, the value of pre-determining roles for learners has gained significant momentum in the field of CSCL, with evidence that it can promote successful collaborative learning in challenging environments, such as when group members interact via technology (e.g., Cesareni, Cacciamani \& Fujita, 2016; Cheng, Wang, \& Mercer, 2014; De Wever, Van Keer, Schellens, \& Valcke, 2009, 2010; Gu et al., , 2015; Morris et al., 2010; Pozzi, 2011; Schellens, Van Keer, De Wever, \& Valcke, 2007; Strijbos et al., 2004). For instance, $\mathrm{Gu}$ et al. (2015) designed a role structure for university students including six assigned roles (starter, supporter, arguer, questioner, challenger, timer), accompanied with prompts how to play each role, to promote meaningful engagement as well as active participation during problem solving in a CSCLenvironment. Similarly, Morris et al. (2010) have used scripted roles such as predictor, summarizer, questioner, and clarifier to scaffold students collaboration in the CSCL-environment gStudy. Other researchers have investigated the effects of role assigning to collaborative learning outcomes. For example, Strijbos et al. (2004) investigated the effects of pre-scribed roles on collaboration and group performance, compared to groups for which roles were not pre-assigned (i.e., groups had to self-organise and coordinate their collaborative activities). In that study, groups of university students had to undertake a group project, where group communication was carried out via e-mail. For the groups in the assigned roles condition, four roles with specific tasks were developed and assigned: project planner, communicator, editor, and data collector. The findings indicated that assigned roles had no effect on group performance in terms of group-level grade, but elicited more task-related statements and increased students' awareness about collaboration. The positive effect of assigning roles has been also documented in research on knowledge construction; for example, pre-scribed roles of starter, summarizer, moderator, theoretician and source searcher in asynchronous discussion boards were found positively linked to levels of social knowledge construction in a study of De Wever et al. (2009; see also 2010; Schellens et al., 2007).

While the importance of studying roles in authentic settings has been highlighted (Morris et al., 2010), pre-determining roles have posed some thorny issues in research on both CSCL and face-to-face learning, and this regardless of their benefits and positive effects. First, as assigned roles commonly involve only a given set of roles that have already been considered meaningful for productive collaboration prior to the activity, roles that may emerge spontaneously and naturally during the activity remain unacknowledged. These may include productive roles but also a whole range of roles stretching all the way to the possible impact of more counterproductive roles (Hogan, 1999; Lehmann-Willenbrock et al., 2016). Second, it can be argued that allowing a student to play one single role at a time during an activity is too static and not adequate to characterize individuals' behaviour in dynamic contexts where roles are naturally in a state of constant flux among group members (Salazar, 1996; Sarmiento \& Shumar, 2010). Third, the fact that assigned roles are typically designed and operationalized with a particular activity and group of students in mind has restrained the establishment of more scalable analytical frameworks in the field (Strijbos \& Laat, 2010). Such arguments stress the importance of shifting the focus of research on roles in collaborative learning from fixed roles to roles that spontaneously emerge and evolve, and of developing frameworks that are suitable to understand and analyse such roles across collaborative learning settings.

Although there has been overall much less research on type of roles that emerge spontaneously and are self-adopted by the students (i.e., emergent role approach, see Strijbos \& Weinberger, 2010), this research has yielded some empirical support for the arguments and shortcomings detailed above. A few of these studies has been conducted in collaborative science learning context. For instance, Hogan's study (1999) investigated group discussions of secondary school students, whose task was to engage to co-construction of knowledge to make sense and explain science phenomena they had observed in a laboratory setting. Through video-observations, she discerned eight roles enacted spontaneously by the students in this group activity: four of the roles were found to promote co-construction (promoter of reflection, contributor of content knowledge, modeller, mediator), and four, also spontaneously enacted were found to impede co-construction (promoter of acrimony, distractor, promoter of simple task completion or unreflective acceptance of ideas, reticent). In that study, however, roles were conceptualized as consistent patterns of behaviours over time, which did not allow a fine-grained investigation of how roles fluctuate dynamically in situ among the group members (see also Maloney, 2007). Two recent 
studies (Volet et al., 2017; Volet, Jones, \& Vauras, 2019) demonstrated the benefits of adopting such a fine-grained analytical approach. For example, the study of Volet et al. (2017) revealed that students were able to flexibly enact wide range of roles during the process of collaborative concept mapping. Moreover, in the groups that produced higher-quality concept maps, students displayed greater flexibility in the enactment of roles featuring deeper cognitive processing of the science content (e.g., knowledge provider, challenger) compared to the groups of students that produced concept maps of a lower quality.

One major limitation of empirical studies on emergent roles, however, is that they rarely extend beyond a single learning setting, which limits the generalisability of the conceptual framework underpinning the study and its findings. A few attempts, however, have been to develop more cohesive and scalable frameworks of emergent roles in certain specific collaborative learning contexts. One of the most comprehensive efforts to date is by Strijbos and Laat (2010), who, after reviewing prior CSCL role literature, proposed a conceptual framework of roles at three levels: i) micro (role as a task), ii) meso (role as a pattern), and iii) macro (role as a stance). Furthermore, they used two asynchronous CSCL datasets to illustrate the viability of the conceptual framework on the macro level, that is, "[a]n individual's participative pattern based on their attitude towards the task and collaborative learning" (p. 497). The participative stances consist of four roles at the small-group level (e.g., ghost, over-rider) and the correspondence of those roles to larger groups (cf. e.g., lurker, generator). As the framework of Strijbos and Laat (2010) was developed in the context of CSCL, its adoptability in research into face-to-face learning would need to be established. In addition, the approach of participative stances may not be sufficient enough if the aim is to focus on roles that are expected to fluctuate and be enacted dynamically in situ during the activity (cf. micro-level). Notwithstanding, scrutinization of several datasets (Strijbos \& Laat, 2010) seems logical in order to identify possible commonalities and discrepancies also between such roles and in different types of learning context. Thereby, a cross-dataset approach was adopted in the present study, to explore the emerging nature of core and activity-specific functional participatory roles in collaborative science learning.

\section{Understanding emerging functional participatory roles in collaborative science learn- ing}

Following Benne and Sheats (1948, 2007), Forsyth (2014), and Oliveira, Boz, Broadwell, and Sadler (2014), it is posited that task-roles naturally emerging in situ are largely functional, in the sense that they emerge due to group members' attempts to address and fulfil task-related demands of the ongoing activity. Moreover, and consistent with Marcos-García, Monés, and Dimitriadis (2015) and Volet et al., (2017), when roles emerge, they manifest themselves through individual participation in group interaction, thereby become observable. Thus, the aim in the present study was to contribute to research on the emergence of roles by proposing a conceptualization of functional participatory roles, which can be defined as the specific strategies and behaviours used by an individual in a particular situation (cf. Volet et al., 2017). This stresses the spontaneous, dynamic, and interactive nature of roles in small task groups (Lehmann-Willenbrock et al., 2016; Salazar, 1996), and is consistent with a categorization of roles as understood at the micro-level (see Strijbos \& Laat, 2010).

In sum, the main aim of this article is to empirically scrutinize the usefulness of the proposed conceptual framework of spontaneously enacted core and activity-specific functional participatory roles in collaborative science learning. A key assumption underlying the framework is that some task-related roles resemble each other across collaborative learning activities. These are thus called core roles, whereas other roles that display more specific characteristics and vary across science activities are called activity-specific roles. Consequently, consistent with their common function across collaborative science-learning tasks (i.e., learn and understand the science content), the core roles are assumed to be more intimately linked to the nature of the science discipline itself, while activity-specific roles are expected to be dependent on affordances and characteristics of the learning activity, environment, and 
task demand. The proposed framework is therefore in line with some researchers' claims that there are both commonalities and discrepancies in roles emerging in diverse small-group settings (e.g., Driskell et al., 2017; Strijbos \& Laat, 2010). Data from three diverse learning environments (two involving one and the third involving two learning activities) were scrutinized to examine the extent of empirical support for the assumption of emerging, functional, core and activity-specific participatory roles in studentled collaborative science learning.

\subsection{A search for empirical support}

The datasets scrutinized for empirical support for this assumption come from three recent studies. Each of these studies aimed to explore the conceptual usefulness of the construct of roles in order to understand individual contributions in productive, student-led collaborative science learning. The first study addressed the scarce evidence of emergent roles in collaborative science learning (Volet et al, 2017). An original coding system was developed to analyse naturally emerging roles in collaborative concept mapping. A second study (Heinimäki, Salo, \& Vauras, 2019) extended the conceptual grounding by adapting the original coding system to the study of a virtual collaborative science-learning environment. Finally, a third study adapted the original coding system to analyse roles in hands-on collaborative science-learning activities (Volet et al., 2019).

In order to capture the expected constant fluctuation of roles from ongoing group interaction, all three studies employed video-based role analyses conducted at the turn level, meaning that the identification of roles was based on discrete verbal and non-verbal individual contributions (i.e., utterance, nodding one's head, etc.). Inter-rater reliability between two trained independent coders (targeting to at least $20 \%$ of all the analysed turns of each activity) yielded a "substantial" to an "almost perfect" result (see Landis \& Koch, 1977, p. 165) across datasets.

In the next section, each dataset is presented in turn, introduced by a brief summary of the aim, design, methodology and key findings of the study that generated the data and a description of how the coding system used to analyse that dataset was developed or adapted. In addition, a chosen data excerpt from each dataset is provided to illustrate sequences of group interactions, in which emerging functional participatory roles were enacted. This is followed by a synthesis of the outcomes from the three datasets and a comprehensive overview of the indicators of core and activity-specific roles identified in each dataset, with illustrative examples of each role. All the names mentioned in the excerpts are pseudonyms.

\subsubsection{Dataset 1: Veterinary science students co-constructing a concept map of a real-life clinical case}

The first dataset is derived from a study in which the aim was to use two analytical approaches to understand individual contributions to productive collaborative learning from clinical case-based assignments (Volet et al., 2017). How patterns of self-adopted roles could explain qualitative differences between groups in task performance was explored.

The research site was a mandatory physiology unit, specifically a case-based group assignment designed to provide second-year veterinary science students with early exposure to and opportunities to learn from a randomly assigned real-life clinical case. Small peer groups of five to six students were required to investigate and learn from their case in their own time over a six to seven week period (see Khosa, Volet, \& Bolton, 2010, 2014; Khosa \& Volet, 2013, 2014; Vauras, Volet, \& Nolen, 2019; Volet et al., 2017). Towards the end of that period, the groups were invited to construct together and without time limit, a meaningful conceptual map of their respective clinical case. A set of cards featuring their case was provided as well as a pen to draw either unidirectional arrows (representing cause and effect relationships) or bidirectional arrows (representing inter-related relationships) between concepts. This totally student-led activity was video-taped, and the video-footage used to identify and analyse the enacted roles emerging naturally during the activity. The quality of the groups' concept maps was assessed through comparison with the maps of clinical experts. Based on this evaluation, two groups with high and two groups with low quality conceptual maps were chosen for the role analysis. This sampling made 
it possible to explore how the different self-adopted roles may have contributed to explain the differences in quality of group performance, and it provided some empirical support for the functionality of the role-coding system across differently performing groups. The main findings were that roles reflecting deep cognitive processing of the science content, in contrast to just sharing opinions without reference to science, and flexible enactment of roles with such a cognitive focus (see descriptions below), were more common in the groups that produced concept maps of a higher quality.

Development of the role-coding system for Dataset 1 . The original coding system was developed primarily based on the typologies of functional roles by Benne and Sheats $(1948,2007)$ and of productive roles by Chiu (2000), and were further adapted to frame the role data in the particular sciencelearning context. After several rounds of data scrutinization (see Volet et al., 2017 for full description), altogether, ten discrete task-roles were identified and allocated to three broader foci representing respectively, roles that focus on science content (knowledge seeker/provider, information seeker/giver), evaluations on science content and previous actions (challenger, supporter, follower), and personal opinions and viewpoints about the activity (opinion seeker/giver). These roles are next briefly described:

- the information seeker and information giver feature sharing of task-related facts and information or seeking this kind of information;

- the knowledge seeker and knowledge provider delve deeper into the content, for example, through providing more elaborated scientific knowledge such as explanations, effects or relations between concepts. 'Providing' (not 'giving') knowledge was used to stress that knowledge cannot be 'handed over' to a contrastingly 'lower' level of facts and information as it is a product of deeper cognitive content processing (see Alexander, 2018);

- the challenger takes a critical standpoint towards suggestions, statements, and actions. Contrary to negative connotations the term criticize may carry, the challenger aims to contribute mainly positively to the group's performance by, for example, seeking further justifications or suggesting alternative solutions, which could lead to a better quality of task performance as a group;

- the supporter endorses statements, ideas, and actions. The supporter may, for example, state previous comments in other words to bring further clarity and, simultaneously, show support for and agreement with the contributions of others;

- the follower also expresses agreement through, for example, utterances such as "Yeah", "OK", or non-verbal behaviour (e.g., a head nod). However, the follower fails to offer more constructive contributions in relation to task completion (cf. null action; see Chiu, 2000), which, thereby, differentiates it distinctly from the supporter role; and

- the opinion seeker and opinion giver produce statements and comments related mostly to procedural matters, such as how to proceed and what to do next. The term 'opinion' stresses that the statements in question can be counted as a personal viewpoint regarding the matter at hand as they are not justified by any scientific content (such as facts or knowledge) and, thus, not conceived as (observationally apparent) attempts to contribute to deeper science-based discourse.

Data excerpt from Dataset 1 . The first excerpt is taken from a situation during concept mapping of the clinical case, where the group is trying to understand the relationship between two concepts. This particular group of five students were successful in their efforts to co-construct a meaningful concept map, since their group product was the one evaluated as of the highest quality of all the four groups investigated in the study (see Volet et al., 2017). This is in line with the following excerpt, which demonstrates how the students enacted flexibly functional participatory roles that focused on making sense of the science content needed to solve the problem at hand. 
Data excerpt 1.

Veterinary science students co-constructing a concept map.

\begin{tabular}{|c|c|c|}
\hline Student & Dialogue & Role \\
\hline Renee & Okay which way? & Opinion seeker \\
\hline Matt & Oh I think a double arrow... do you think... & Opinion giver \\
\hline Renee & A double arrow you reckon? Weight loss wouldn't cause azotaemia. & Challenger \\
\hline Blanca & No just one arrow. & Opinion giver \\
\hline Renee & Azotaemia would cause weight loss? & Challenger \\
\hline Blanca & Yeah. & Knowledge provider \\
\hline Renee & Nooo. & Challenger \\
\hline Blanca & Why not? & Challenger \\
\hline Renee & $\begin{array}{l}\text { Because the azotaemia doesn't like burn up calories the azotaemia just } \\
\text { makes them sick. }\end{array}$ & Knowledge provider \\
\hline Blanca & $\begin{array}{l}\text { Well all right, so why don't you move that- (pointing towards board } \\
\text { but gets interrupted). }\end{array}$ & Opinion giver \\
\hline Thea & Theoretically weight loss can cause azotaemia. & Knowledge provider \\
\hline Renee & Sorry (asks to repeat)? & Follower \\
\hline Thea & Theoretically weight loss can cause azotaemia. & Knowledge provider \\
\hline Renee & It can? Okay... & Follower \\
\hline Thea & $\begin{array}{l}\text { By breaking down more protein therefore you've got more urea in your } \\
\text { system. }\end{array}$ & Knowledge provider \\
\hline Winnie & Yeah, mmm. & Follower \\
\hline Matt & Aaaahhh. & Follower \\
\hline Renee & That's good... & \\
\hline Blanca & Nice one... & \\
\hline Renee & $\begin{array}{l}\text { Mmm that was really good. See there was a reason we moved them ... } \\
\text { (the group moved to applaud Thea for providing a reasonable solution) }\end{array}$ & \\
\hline
\end{tabular}

For starters, Matt initiated the discussion based on Renee's question about the relationship of weight loss and azotaemia, but he did not provide scientific backup for his suggestions, thus stayed in opinion sharing realm. However, this triggered a sequence of self-adopted roles among group members that is manifested in group interaction through intensive exchange of ideas, arguments, challenging of previous statements and co-construction of knowledge. After having a while listened this exchange, Thea contributed to the discussion by providing a solution to the question. After Thea justified her claim with even more convincing evidence in the capacity of knowledge provider role, the group quickly found a common consent on the matter, and started applauding Thea for her solution.

\subsubsection{Dataset 2: Senior high school general science students experimenting in a virtual environment}

The second dataset comes from a study in which roles were used to evaluate the collaborative science learning of senior high school students in a virtual learning environment (Heinimäki et al., 2019). The study aimed to establish a coding system of functional participatory roles for this learning context, and use data excerpts to demonstrate the viability of that coding system for fine-grained analyse of roles from group interactions. Further, analytical descriptions of these data excerpts from a standpoint of roles were demonstrated to provide meaningful insights into understanding the process and quality of collaborative interactions in different task situations.

The participants were senior high school general science students enrolled in advanced-level courses in chemistry and biology. During three lessons (75-90 minutes each), small student groups participated in a virtual expedition on a research vessel in a virtual web-based science-learning environment, Virtual Baltic Sea Explorer (ViBSE), designed to provide students with a realistic research context and an inspiring set of tools to co-construct integrated knowledge with their peers in two disciplines: 
chemistry and biology (see Pietarinen, Vauras, Laakkonen, Kinnunen, \& Volet, 2019; Vauras, Telenius, Yli-Panula, Iiskala, Pietarinen, \& Kinnunen, 2017; Vauras et al., 2019). Each group worked at their own table in a face-to-face setting with a laptop, which was used to operate the virtual learning environment. The scrutinization of roles in the study of Heinimäki et al. (2019) included video observations of six groups of triads undertaking a study on the effects of $\mathrm{pH}$ changes on a certain species of copepods. In doing this, the groups had to design their study, set hypotheses, carry out experiments by using authentic data from marine biologists, analyse the results, and draw conclusions based on their outcomes. The groups conducted this activity largely autonomously, but teacher support was available if needed. Finally, each group produced a presentation describing their study and conclusions (i.e., group outcome) (see Vauras et al., 2019). The quality of the group outcome was assessed (on the 6-level scale) by science experts in biology and chemistry; the criteria comprised the structure of the presentation, understanding of the task, hypotheses, research plan, conclusions and the quality of scientific language used in the presentation. The groups selected for the present article represented six diverse groups in terms of the level of the group outcome. The same groups were used in Heinimäki et al. (2019), the article that reported the validation of the coding system of the roles enacted by senior high school students.

Development of the role-coding system for Dataset 2. The development of the coding system for the data started with an evaluation of the functionality of the original role-coding system (Volet al., 2017) to analyse roles emerging in the different type of science learning context. To accommodate these discrepancies, roles were investigated using data-driven methods, too. The original coding system proved usable as each of its roles were identified from the data at hand as well. However, new types of roles also emerged, calling for the inclusion of additional roles in the coding system under construction. In the end, five activity-specific roles were identified and incorporated into the coding system. In addition, some of the original sub-categories of task-roles (see section 2.1.1) were slightly modified, and a category of experiment and process-focused roles was formed to better fit the context of the experimental activity. Accordingly, some fine tuning was made to the conceptualization of some distinct roles to accommodate them better to the data at hand.

Five newly emerged activity-specific roles were closely linked both to the functional demands of conducting the task in the virtual environment and the digital tools involved in the activity:

- the navigator is responsible for moving the group around (e.g., between research phases) in ViBSE by using the mouse and the keyboard of the laptop provided for the group;

- the attention focuser attempts to focus the attention of the group members on something related to the task content;

- the recorder performs activities related to keeping records of decisions made and manual controlling of variables in the virtual laboratory;

- the dictator is closely linked with recording activities; for example, when the outcomes of a joint group discussion are dictated to be further recorded (e.g., what to write in group's presentation); and

- the technological contributor performs actions, gives instructions and asks questions related to use of technology in relation to task performance.

Data excerpt from Dataset 2: The second excerpt is drawn from a phase of the activity where the group engages to interpret the results of their experiments. This group was categorized as a highoutcome group based on the quality of the presentation they later gave to the rest of the class (see Heinimäki et al., 2019). The following excerpt not just illustrates the interactive nature of functional participatory roles self-adopted in the situation, but also the role the affordances and constrains of the virtual learning environment played in shaping group interaction. 
Data excerpt 2.

High school general science students interpreting the results of their virtual experiment.

\begin{tabular}{|c|c|c|}
\hline Student & Dialogue & Role \\
\hline Ellen & ... this was very interesting (sarcasm), but now let's move forward. & Opinion giver \\
\hline Sofia & Ok. & Follower \\
\hline Sofia & $\begin{array}{l}\text { (operates the mouse to move the group forward to a phase where they } \\
\text { will conduct an experiment in the virtual laboratory). }\end{array}$ & Navigator \\
\hline Sofia & $\begin{array}{l}\text { We had thirty hours (informs what type of conditions the group had } \\
\text { chosen). }\end{array}$ & Information giver \\
\hline Sofia & Is that (inaudible)...? & Information seeker \\
\hline Ellen & Yep. & Information giver \\
\hline Paula & What was that first one again? & Information seeker \\
\hline Ellen & It was about the eggs. & Information giver \\
\hline Sofia & It was about the quantity of the eggs- & \\
\hline Paula & So now they developed. & Information giver \\
\hline Sofia & $\begin{array}{l}\text { (continues her previous comment) - so basically our first hypothesis } \\
\text { was incorrect, because we expected that it (the experiment) would have } \\
\text { had a negative effect to egg production. }\end{array}$ & Knowledge provider \\
\hline Ellen & Yes. & Follower \\
\hline Paula & But it, in fact, had a positive effect. & Supporter \\
\hline Ellen & Click that ' 30 ' (points at the screen). & Attention focuser \\
\hline Sofia & Yeah (clicks and the software calculates the results). & Recorder \\
\hline Sofia & $\begin{array}{l}\text { Okay, ambient... so in that decreased (condition) the quantity of those } \\
\text { things (hatched eggs) was higher, the quantity for the hatched ones was } \\
\text { higher. }\end{array}$ & Information giver \\
\hline Ellen & Yep. & Follower \\
\hline Sofia & $\begin{array}{l}\text { Count means (verbalizes her actions while clicking a button in the envi- } \\
\text { ronment). }\end{array}$ & Recorder \\
\hline Ellen & Oh dear, why they are like this (the results)!? & Knowledge seeker \\
\hline Paula & We performed quite poorly. & Opinion giver \\
\hline Ellen & $\begin{array}{l}\text { We were totally wrong. } \\
\text { (the group overcame their disappointment a while and moved on) }\end{array}$ & Information giver \\
\hline
\end{tabular}

The excerpt emerges at a point when the group is about getting stuck discussing irrelevant issues. At this point, Ellen encourages the group to move forward with the task. The opinion giver role adopted by Ellen demonstrates the impact of the virtual environment and the technology involved in this specific activity. The activity-specific roles of navigator, recorder and attention focused enacted after this, further illustrate the impact of the activity on the enacted roles. The emergence of this pattern of roles was triggered by the fact that the groups had to operate with only one mouse, keyboard and screen, which means that only one student at a time could use the technology (in this excerpt Sofia). This environmental constraint had implications on the roles Sofia enacted (e.g., navigator, recorder) in situ, but also impacted on the other students who had to describe very clearly the actions they wanted the person operating the equipment to perform during the evolving activity (e.g., opinion giver role adopted by Ellen). In addition, the excerpt illustrates the emergent nature and affordances of the activity as the group conducts their experiments in the virtual laboratory. For instance, the group received some results immediately, and in this case the results were unexpected. The first reaction of Ellen was to understand the scientific reasons for it (knowledge seeker), whereas Paula just settled by stating that they performed poorly as a group with no scientific interest (opinion giver). 


\subsubsection{Dataset 3: Preservice primary school teachers' conducting hands-on science experiments}

The third dataset is derived from a study in which preservice primary school student teachers' attitudes and productive engagement in collaborative science learning within a mandatory introductory science course was investigated (Volet et al., 2019). Productive engagement was investigated through the task-focused roles spontaneously enacted by the students during two hands-on science laboratory activities grounded in a scientific inquiry approach and undertaken in small groups (see Pino-Pasternack \& Volet, 2018; Volet et al., 2019).

The first activity focused on learning about chemical reactions, which was investigated through fair tests with small 'rockets'. The groups had to design their test, develop research questions and hypotheses, choose research variables, conduct their test, and interpret the results; this activity was also aimed at promoting students' understanding about the fundamentals of carrying out a scientific investigation. The second activity was more exploratory; the groups investigated how to make electric circuits with play dough and various materials that were provided. This activity aimed mainly at generating meaningful exchange of questions and ideas among the students as they tried to interpret their observations. The laboratory sessions lasted approximately two hours. The groups were video-taped, and emergent task-related roles were analysed from four groups (four students each) that participated in both activities. The groups typically comprised a somewhat heterogeneous mix of students regarding prior science skills and attitudes towards learning science (see Volet et al., 2019). The role analysis revealed that, overall, roles focusing on science content and experimenting-related activities were more commonly enacted in the first, more structured activity ('rocket'), whereas opinion sharing focused roles were in comparison more prevalent in the second, more exploratory activity ('circuit'). The analysis of roles also revealed finer distinctions in relation to attitude-, and group-related differences in the quality of individual and group engagement in the two activities (see Volet et al., 2019).

Development of the role-coding system for Dataset 3. A procedure similar to that described for the previously described dataset (see section 2.1.2) was followed: this included establishing the relevance of the original coding system (Volet et al., 2017) for the data at hand and data-driven investigation of other activity-specific roles which may have emerged during the two science activities. Again, all the roles described by Volet et al. (2017) were identified, but some minor modifications that were quite similar to those described in the case of Dataset 2 were implemented to adapt the coding system for this specific study. Altogether, three activity-specific roles were identified. Again, these roles largely interweaved with the procedural task performance, and materials/tools involved in the hands-on experiments.

- the reader reads instructions or other information aloud for the group. This was typically from the lab manual that was provided to each student;

- the procedural contributor focuses on processes and procedures such as by providing general comments about the materials, filling in answers in the lab manual, and taking notes, which do not include contributions involving (observably apparent) deep cognitive processing of the science content (e.g., scientific explanations); and

- the observation maker conducts rather straightforward observations towards, for example, what is occurring during the hands-on experiment.

Data excerpt from Dataset 3: The third excerpt is from the activity which focused on chemical reactions ('rocket'), and is taken from a specific phase in which the group was planning their experiment. A few utterances showing agreement and other low-level contributions (i.e., follower role) were removed to shorten the excerpt. The number of self-adopted roles focusing on science content within that group was the lowest across all four groups investigated in that study (see Volet et al., 2019), which is also consistent with the dialogue in the following excerpt. 
Data excerpt 3.

Preservice primary school teachers' planning a hands-on science experiment.

\begin{tabular}{|c|c|c|}
\hline Student & Dialogue & Role \\
\hline Milly & Maybe we should do bicarb and vinegar. & Opinion giver \\
\hline Gina & Bicarb and vinegar, or Coke and Mentos. Those two I know will fizz. & Information giver \\
\hline Milly & $\begin{array}{l}\text { I don't think water would do anything except though if it's with the } \\
\text { Eno (i.e., medicinal tablet used in the experiment), maybe, because it } \\
\text { fizzes up. }\end{array}$ & Opinion giver \\
\hline Milly & But to make enough pressure I don't think go anywhere-- & Opinion giver \\
\hline Gina & Yeah. & Follower \\
\hline Helen & So which one are we gonna do? & Opinion seeker \\
\hline Gina & Shall we do vinegar and bicarb? & Opinion seeker \\
\hline Sharon & Yeah let's do that. & Opinion giver \\
\hline Helen & Okay (all nod). & Follower \\
\hline Milly & $\begin{array}{l}\text { How are we gonna measure it? Maybe the time that it's up there? So } \\
\text { we can just ah, from the time it takes off till the time it falls to the } \\
\text { floor. }\end{array}$ & Information giver \\
\hline Gina & Would that be hard to test? & Opinion seeker \\
\hline Milly & You just get a timer. & Opinion giver \\
\hline Sharon & $\begin{array}{l}\text { As soon as it leaves the floor you've just got to time the ssh shhh (im- } \\
\text { itating a stopwatch sound). }\end{array}$ & Opinion giver \\
\hline Sharon & $\begin{array}{l}\text { And when the energy runs out it goes whoooo (gesturing to show } \\
\text { something falling). }\end{array}$ & Opinion giver \\
\hline Milly & So what are we gonna write? How long it's in the air? & Opinion seeker \\
\hline Gina & We're going to investigate the time, ah- & Opinion giver \\
\hline Sharon & The time of the reaction? The- (making upwards gesture with hand). & Information giver \\
\hline Helen & The time it stops reacting to the time it takes off. & Information giver \\
\hline Gina & Yeah the time it takes off to the time it- & Follower \\
\hline Gina & $\begin{array}{l}\text { The time of the reaction from when the rocket leaves the floor, till it } \\
\text { hits the floor. }\end{array}$ & Information giver \\
\hline Helen & $\begin{array}{l}\text { So what do we predict what happens? (yawning, and then providing } \\
\text { the question from lab book). }\end{array}$ & Procedural contributor \\
\hline Sharon & Think it'll just react straight away. & Opinion giver \\
\hline Helen & Fizz up and take off straight away. & Follower \\
\hline Gina & I don't reckon it will go very high though. & Opinion giver \\
\hline
\end{tabular}

The quality of this group interaction remained at low level throughout the excerpt in reference to science, as students enacted primarily roles that were in the opinion and procedural realms. For instance, as they went on with planning and decision making, the students relied largely on their personal opinions about the matter. A few times an attempt was made to encourage a science-based discourse through the role of information giver, but these events did not trigger any sustained and deep sciencebased argumentation or knowledge co-construction. In this respect, the observed pattern of enacted roles within this group was very different compared to the exchange illustrated earlier with veterinary students in data excerpt 1. 


\subsection{Summary}

The investigation of task-related roles in each of the three datasets provided support for the assumption of spontaneously enacted core and activity-specific roles during collaborative science learning. Nine roles were commonly found across all learning environments and could therefore be conceptualized as core roles. Table 1 provides a definition and indicators for each of these core roles, with examples from the different datasets as illustrations. These definitions and indicators are, however, not assumed to be totally rigid and allow for some flexibility. For example, some slight adaptations were made to the conceptualisation of the roles of knowledge provider/seeker and opinion giver/seeker in both Datasets 2 and 3 to reach a better correspondence with the functions that these roles actually played in those activities (e.g., the nature of acquired knowledge slightly varied depending on the characteristics of an activity).

Furthermore, and consistent with the assumption, there was evidence that some roles were only enacted in certain activities and could therefore be conceptualized as activity-specific roles. Table 2 provides a definition and indicators of these roles, with examples from the different datasets. In the tables, core and activity-specific roles were grouped under a broad classification of task-related roles, although more detailed classifications into sub-categories would be plausible. For example, the taskrelated roles identified in the initial study (Volet et al., 2017) were allocated to three distinct foci, each capturing a different form of engagement in the collaborative science-learning activity (see section 2.1.1). These sub-categories were, however, re-arranged in the analysis of the two subsequent datasets in order to better fit with the context of experimental activities. Importantly, rigid sub-categories were avoided in order to keep the framework as flexible as possible. 
Table 1

Overview of core roles in collaborative science learning

\begin{tabular}{cl}
\hline Roles & \multicolumn{1}{c}{ Definitions \& indicators } \\
\hline $\begin{array}{c}\text { Knowledge } \\
\text { seeker (KS) }\end{array}$ & $\begin{array}{l}\text { KS attempts to gain deeper understanding in relation to science content without being } \\
\text { critical of previous comments or actions. KS is especially interested in scientific expla- } \\
\text { nations, cause and effects. }\end{array}$ \\
$\begin{array}{cl}\text { Knowledge } \\
\text { provider } \\
\text { (KP) }\end{array}$ & $\begin{array}{l}\text { KP offers scientific explanations, effects, causes and other deep content-related } \\
\text { knowledge. KP can shape existing facts and information and introduce how they would } \\
\text { work if adopted by the group, and in this way, KP can provide new solutions or initiate } \\
\text { something new for the group. }\end{array}$
\end{tabular}

Information IS seeks facts and information related to content without being critical of previous

seeker (IS) comments or actions. For seeking deeper understanding, effects or interrelations, code $\mathrm{KS}$ is used.

Information IG offers content-related facts and information without being critical of previous comgiver (IG) ments or actions. For deeper information and scientific explanations, code KP is used.

Challenger $\mathrm{CH}$ puts previous actions, suggestions and content-related comments to a test and is in(CH) terested in exploring alternatives. $\mathrm{CH}$ can offer alternative solutions or also invite others to evaluate suggestions or actions.

\section{Data examples}

"Are ascites and proteinemia linked in any way?" 1

"What happens with the eggs?" ${ }_{2}$

"Why would it have gotten brighter though?" ${ }_{3}$

"Well cos cardiomyopathy is our, is the central cause, so it's a single head to VPC to congestive heart failure to arrhythmia."

"... Our first hypothesis proved incorrect because we hypothesized it would have a negative effect on the egg production." 2

"Because the lights are polarized." 3

"Did our dog have ear infection at all?" 1

"Was it correct?" 2

"What's a simple circuit, and what's a parallel circuit?" 3

"We had mild, mild kidney." 1

"So, there was more in the smaller one." 2

"There's not enough power." 3

"Why would hypertension cause you to drink more?" 1

"Yes, maybe relatively, but if it happens to these ones [copepods], it could be expected to happen with other species, too." 2

"No, if you put them in here. The two different ones act like an insulator." ${ }_{3}$ 
Supporter SU backs up ideas or suggestions made with added clarity, for example, stating previ(SU) ous comments in slightly different words or with supportive additions, clearly from a supportive standpoint. If a new type of information is added, code IG or KP is used.

Follower FO indicates on-task-related agreement verbally or non-verbally (e.g., a nod) without offering additional facts, knowledge or opinions. FO can also admit the lack of a personal contribution and thus readiness to go along with the decisions of others. FO may also just repeat, or ask others to repeat, statements and suggestions.

Opinion OS tries to get the others to express their opinions on something related to procedures seeker (OS) or to content, for example, how to proceed and what opinion to choose. OS is not interested in facts, knowledge or seeking science-based justifications.

Opinion OG gives opinions related to procedures or content, for example, how to proceed and giver (OG) what option to choose. OG does not offer science-based facts or knowledge to justify suggestions or statements.
"It's like a stabilizer.", 1

"Yep, yep. It kind of follows them [makes a following type of gesture with hands]."

"Yeah, check the other side" [in response to: "Turn it around..." ]. ${ }^{3}$

"I don't remember." 1

"Yep." 2

"Just go with it." 3

"Where do you want them?" 1

"Do we go backwards?" ${ }_{2}$

"What's our best one?" 3

"Maybe like two of us try and do it and the rest of us just stand back like." 1

"Let's just straightforwardly put that it increases." 2 “...I feel like it's brighter." 3

Note. The numbers refer to the dataset from which the example is derived (e.g., ${ }^{1}=$ data example derived from Dataset 1$)$. 
Table 2

Overview of activity-specific roles in collaborative science learning

\begin{tabular}{|c|c|}
\hline Roles & Definitions \& indicators \\
\hline $\begin{array}{l}\text { Navigator } \\
(\mathrm{NV})^{2}\end{array}$ & $\begin{array}{l}\text { NV answers for navigating the group in the virtual environment either independently or } \\
\text { based on suggestions of other group members. }\end{array}$ \\
\hline $\begin{array}{c}\text { Attention } \\
\text { focuser }(\mathrm{AF})^{2}\end{array}$ & $\begin{array}{l}\text { AF draws other group members' attention to something related to the task either ver- } \\
\text { bally (e.g., reading aloud) or non-verbally (e.g., pointing at computer screen with a fin- } \\
\text { ger). }\end{array}$ \\
\hline $\begin{array}{l}\text { Recorder } \\
(\mathrm{RE})^{2}\end{array}$ & $\begin{array}{l}\text { RE focuses on recording group activities for the group, for example, by taking notes or } \\
\text { constructing the group's joint presentation. RE also enters and manipulates variables } \\
\text { while the group is conducting their experiment in the virtual laboratory. RE does not } \\
\text { challenge suggestions or statements made by the other group members. }\end{array}$ \\
\hline Dictator $(\mathrm{DI})^{2}$ & $\begin{array}{l}\text { DI dictates what to record (e.g., write) or how to proceed (e.g., which option to choose) } \\
\text { based on the group's joint discussion or decisions made. DI does not provide new in- } \\
\text { formation. When a more general and personal comment or suggestion is in question, } \\
\text { code OG is used. }\end{array}$ \\
\hline $\begin{array}{l}\text { Technological } \\
\text { contributor } \\
\quad(\mathrm{TC})^{2}\end{array}$ & $\begin{array}{l}\text { TC focuses on technological matters, such as giving instructions or raising and solving } \\
\text { issues related to technology in relation to task performance. }\end{array}$ \\
\hline Reader $(\mathrm{RD})^{3}$ & $\begin{array}{l}\text { RD reads aloud instructions or information relating to the experiment for the group to } \\
\text { understand how to proceed. This may be from the lab manual, other instructions, or in- } \\
\text { formation from lectures or lab notes. }\end{array}$ \\
\hline $\begin{array}{l}\text { Procedural } \\
\text { contributor } \\
\quad(\mathrm{PC})^{3}\end{array}$ & $\begin{array}{l}\text { PC focuses on processes/procedures: writing answers to questions in the lab manual, } \\
\text { recording notes, and giving generic comments about materials. If new information or } \\
\text { explanations not previously discussed are provided, either code IG or KP is used. }\end{array}$ \\
\hline
\end{tabular}

(Table 2 continued) 
Observation OM draws other group members' attention to something related to the "hands-on" exmaker $(\mathrm{OM})^{3}$ periment and materials that the group is dealing with. OM can, for example, point out something happening in the lab experiment by verbalizing simple observations.
"The front four go brighter." 3

Note. The numbers refer to the dataset in which the role was identified and from which the example is derived (e.g., ${ }^{2}=$ role/data example derived from Dataset 2). 


\section{Discussion}

Student-led collaborative learning in science has become increasingly common at different levels of education. Yet, to date, the roles spontaneously enacted by students during these types of collaborative activities have received limited empirical attention - prior research focusing mainly on preassigned roles in small task groups (e.g., Gu et al., 2015; Morris et al., 2010; Pozzi, 2011; Strijbos et al., 2004; for a review, see Cohen, 1994). By focusing on a single learning setting and typically downplaying the spontaneous, emergent and interactional nature of roles (see Oliveira et al., 2014; Lehmann-Willenbrock et al., 2016; Salazar, 1996), prior research has limited the development of generalizable conceptual frameworks aimed at understanding the impact of roles in and across collaborative learning activities as they unfold in real-time.

In this article, empirical support was provided for the importance of paying attention to the emergent and interactional nature of roles in student-led collaborative learning in science and the nature of these roles. Two claims are made. The first claim is that like other key processes in small-task-group learning, such as socially shared metacognitive regulatory processes (e.g., Iiskala, Volet, Lehtinen, \& Vauras, 2015), and emotion and motivation regulation (e.g., Järvenoja, Järvelä, \& Malmberg, in press), there is a need to understand how naturally emerging functional participatory roles meaningfully contribute to learning and task completion. Shifting the emphasis from pre-assigned fixed roles to roles as naturally emerging, evolving, and dynamic in situ is consistent with Greeno's (2006) conceptualization of learning in activity systems "in which learners interact with each other and with material, informational, and conceptual resources in their environment" (p. 92). The empirical support gathered in the present study through the identification of functional participatory roles enacted in the three datasets supports the claim that roles emerge during a group activity through ongoing and intertwined interaction between the group and its environment.

The second claim is grounded in the assumption, supported by empirical evidence from the three datasets, that during collaborative science-learning activities, group members spontaneously enact two types of functional, participatory task-related roles:

a. the core roles reflect inherently the nature of the science discipline (see Anderson, 2007; Duschl \& Hamilton, 2011 for elaboration on the nature of science) and, therefore, the uptake of these roles is at the heart of productive collaborative science learning; and

b. the activity-specific roles depend on the characteristics of the activity, for example, the task demands, context and settings, and, therefore, these roles play an important part in successful collaborative science learning.

Data from the three diverse science-learning environments, including four collaborative science activities, provided empirical support for the assumption that in collaborative science learning, some task-related roles are commonly found across all science-learning activities (i.e., core roles) while others are only found in certain science-learning activities (i.e., activity-specific roles). In spite of notable contextual differences in some aspects (i.e., educational level, student characteristics, learning environment, learning task), similar core roles were observed in the processing of the science content by student groups across environments, domains, and activities. In contrast, the majority of activity-specific roles were linked to the more technical or practical aspects of performing and accomplishing the learning task (i.e., recording progress, navigating in the virtual environment, reading aloud from the lab materials, etc.). For example, the range of activity-specific roles that were identified, such as navigator, technological contributor, and observation maker, emerged and were enacted largely due to specifically situated affordances and constraints related to carrying out the particular activity.

These two empirically supported claims led to the proposal of a flexible conceptual framework for the analysis and understanding of the core and activity-specific functional participatory roles emerging during collaborative science learning (see Figure 1). 


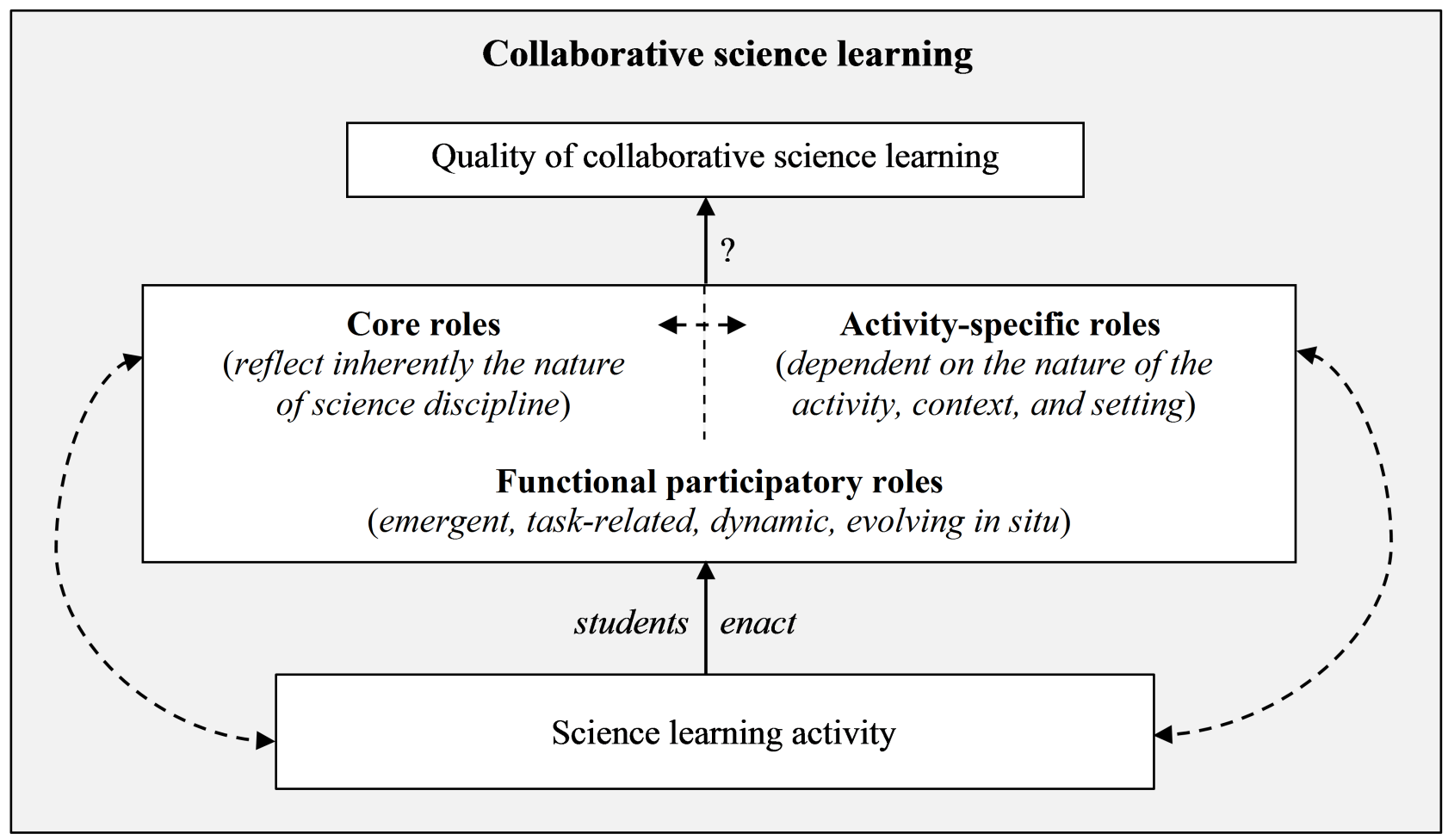

Figure 1. A conceptual framework of the core and activity-specific functional participatory roles emerging during collaborative science learning.

This figure incorporates all the elements of the framework and its underlying claims. Reading from the bottom-up, the figure shows how during science-learning activities carried out in small groups, students enact functional participatory roles which are emergent, task-related, dynamic, and evolve in situ. The middle part of the figure distinguishes the two types of roles that can emerge during an activity, core and activity-specific, and their characteristics and functionality regarding learning and task completion are specified. The dotted lines with bi-directional arrows between each type of role and the science-learning activity stress the interactive, dynamic, and intertwined nature of roles during an activity. The arrow with a question mark above the box of roles indicates the expected link to the quality of collaborative science learning. Although this aspect was not examined in the present study, other research has provided some empirical support for this relationship (e.g., Volet et al., 2017). The study of Volet et al. (2017), however, did not distinguish between core and activity-specific roles. On the grounds that the emergence of core roles is conceptualized as reflecting inherently the nature of the science discipline, whereas the emergence of activity-specific roles is assumed to depend on the characteristics of the particular science activity, it can be argued that both core and activity-specific roles play an important part in successful collaborative science learning, but how these roles are taken up by group members during an ongoing activity has an impact on the quality of collaborative science learning.

To sum up and conclude, the contributions of the proposed framework for research on collaborative science learning can be understood as threefold:

a. conceptually, shifting the focus from fixed roles to roles that are naturally emerging and evolving in situ is consistent with the literature characterising collaborative learning as highly dynamic (Hadwin et al., 2018; Hilpert \& Marchand, 2018). The adoption of a situative approach to better understand the task-related, functional participatory roles that naturally emerge during collaborative activities addresses an earlier, yet still valid, call that researchers need to acknowledge the significance of roles in a "comprehensive social-psychology theory" (Hare, 1994, p. 434). This approach also addresses Hoadley's (2010) call for the need to understand "where roles come from, and how they might emerge" (Hoadley, 2010, p. 545), which he claimed was not always clearly stated in prior research; 
b. methodologically, identifying two types of functional participatory roles, that is, those commonly enacted during collaboration across science activities and those that are activity-specific, the framework adds value to existing frameworks, which have examined empirically the impact of roles mainly in single learning settings. Thus, the proposed framework addresses the calls for more scalable analytical frameworks that are flexible and sensitive to data specificity as well (cf. Volet \& Summers, 2013). In the present case, a degree of cross-dataset generalizability is reached through the identification of core roles commonly found in diverse collaborative science-learning activities, and sensitivity to data through activity-specific roles that are dependable on the characteristics of the activity; and

c. empirically, as indicated in Figure 1, the framework is expected to provide potential for further analysis of the significance of roles for productive collaborative science learning through investigations of how core and activity-specific roles that are relevant for successful task completion are enacted during collaborative science-learning activities. Thus far, there is some evidence that certain core roles, such as knowledge provider, knowledge seeker, and challenger, can meaningfully explain, for example, attitudes towards learning, engagement in deep learning, and the quality of collaborative science outcomes (Volet et al., 2017, 2019). Although these findings offer reasonable validation for future use of the framework beyond single datasets when the aim is to obtain insights into high-quality collaborative science learning, more research is needed to further establish these relations and gain deeper insight into how activity-specific roles operate in conjunction with core roles in order to strengthen productive collaborative science learning.

In addition, future research aimed at understanding better the importance of core and activityspecific roles in collaborative science-learning bears also practical implications for science education. Teachers may not be used to guiding students during collaborative inquiry learning, since this form of teaching does not necessarily fit the typical structures and norms of classrooms and schools that they are familiar with. Many are often challenged as to how to provide adequate support for student groups, in particular if students are novices without a repertoire of disciplinary practices (Vauras et al., 2019; see also Kirschner, Sweller, \& Clark, 2006). In this respect, a better understanding of how enacted, intertwined functional participatory roles impact on the quality of learning and task completion may provide some guidance to teachers using collaborative learning activities in classrooms. As spontaneously enacted roles serve potentially more readily observable indicators of the quality of groups' productive engagement than, for instance, regulatory processes, such understanding can help teachers to meaningfully calibrate their support and scaffolding to student groups during ongoing collaborative activities. For instance, if non-beneficial or even detrimental role patterns start emerging within a group, an informed teacher could try to intervene in the ongoing interaction early on, before the harmful patterns escalate any further. Teachers can thus also utilize such understanding to inform, model and encourage flexible enactment of the most productive functional participatory roles during collaborative activities. An appreciation of the significance of self-adopted roles could also help teachers and developers design new, facilitative features in collaborative science-learning activities and environments. Furthermore, such an appreciation may contribute to address the possible mismatch between design and reality, meaning that "roles-as-intended" can differ from "roles-as-enacted" (Hoadley, 2010, p. 553). Thus, the observation of roles emerging spontaneously during an activity may be worthwhile exploring further with a view to establish if a particular learning environment actually promotes desired types of behaviours and learning (e.g., high-level co-construction of knowledge; see e.g., Volet et al., 2009; Webb, 2008), i.e. it was designed for or if it actually feeds the uptake of "not-intended" roles.

Finally, it is not surprising that as learning activities are increasingly taking place across diverse settings and contexts, there have been calls for research that unravels both the unique and parallel features across such activities (Ludvigsen, Lund, Rasmussen, \& Säljö, 2011). The proposed framework addresses this call by highlighting the emerging functional participatory roles, both common and unique, found in collaborative science-learning, and at the same time, by making a contribution to the broader ongoing debate over the interplay of domain-generic and domain-specific learning in science (see Duschl \& Hamilton, 2011). 


\subsection{Limitations and other considerations}

It is acknowledged that the empirical support for the assumption of core and activity-specific roles in collaborative science learning is based only on three small datasets. More and larger datasets will be needed for further validation of the proposed conceptual framework and this will be especially important to validate the claim that core roles can, in fact, be found across a wide range of collaborative science-learning activities. The outcome of future investigations may perhaps also lead to a reconsideration of the overall composition of the core roles presented in the present study. For example, given that collaborative learning activities typically involve some kind of recording (i.e., note taking, writing from a dictation, generating a research report, etc.), it could be that bundling up all these behaviours together for analytical purposes would be consistent with the proposal to consider the recorder as a "classic functional role" (Morris et al., 2010, p. 816; see e.g., Benne \& Sheats, 1948, 2007). However, a reductionist approach could end up being problematic as the nature of recording-related activities and behaviours tend to vary extensively between learning environments (cf. e.g., the recorder in Dataset 2 and the procedural contributor in Dataset 3), which could then lead to the risk of oversimplification and the inhibiting of the process of fully capturing the rich activity-specific data in question.

One limitation to the generalizability of the proposed framework is the fact that the data provided as empirical support involved only certain types of collaborative science activities, and was restricted to face-to-face interactions. Nevertheless, although straightforward generalizations cannot be drawn, it is reasonable to expect that this framework could be applicable to some other domains, or at least to collaborative science learning in other STEM (science, technology, engineering, and mathematics) disciplines.

When it comes to asynchronous and distance-learning environments, where group functioning and individual behaviour can somewhat vary compared to face-to-face activities, the proposed framework and its derived coding systems could possibly fall short of capturing certain roles that are characteristic of these environments. Thus, this could lead to a call for a different kind of approach, such as additionally focusing on the macro-level of roles, as suggested by Strijbos and Laat (2010). It would be intriguing to put to the test how the framework would operate in CSCL environments where students interact synchronously, such as in chats (Sarmiento \& Shumar, 2010). It would be especially important to explore what kind of activity-specific roles emerge in these types of environments as the datasets scrutinized in the present article suggest that the number of roles needed to execute task-related functions can be higher in virtual environments compared to more "conventional" learning environments (see Table 2). This is noteworthy from the standpoint of learning and group performance because the task-based demands of mastering multiple different roles can be challenging for the group members (cf. role flexibility; see Benne \& Sheats, 1948, 2007; Forsyth, 2014). One more limitation is linked to the possibility that individuals' behaviour and roles can differ in larger groups compared to smaller sized groups (Forsyth, 2014), which may possibly influence the enactment of roles (Hare, 1994; Strijbos \& Laat, 2010). This suggests that the applicability of the framework should be explored outside of the small-group context. Furthermore, as the samples of students involved in the present study were senior high school and university students, the applicability of the framework and its derived set of core and activity-specific roles should be extended to research with groups of younger students and possibly to workplace environments.

Finally, as the proposed framework focuses exclusively on functional participatory roles that are task-related, future research may also explore the relevance of socio-emotional roles. It could be argued that socio-emotional roles are neither core nor activity-specific but rather emerge at the interface of learner characteristics and activity specificity or that the enactment of these roles is influenced by the atmosphere and orientation of the group towards the collaborative task. For example, if a learning activity is perceived by some students as not taking into consideration their personal goals, interest, motivation, prior skills, and knowledge, this could lead to feelings of frustration and lower engagement, even the development of negativity towards the activity or collaboration with others, and vice versa in terms of more positive socio-emotional roles (cf. Strijbos \& Laat, 2010). This may also influence how taskrelated roles are enacted and, in turn, the quality of the group's task performance. There is no doubt that 
the potential of the proposed framework to represent the significance of roles in authentic, real-life collaborative learning situations will need further validation and exploration.

\section{Keypoints}

- There is a scarcity of scalable frameworks aimed at understanding the significance of roles in and across collaborative science-learning activities.

- The functional participatory roles enacted by group members in collaborative learning are conceptualized as emergent, dynamic, and evolving in situ.

- A flexible conceptual framework for the analysis of emergent functional participatory roles across collaborative learning activities is proposed.

- The framework builds on the assumption that during collaborative learning, both core roles and activity-specific roles are enacted.

- Three collaborative science-learning datasets were scrutinized to establish the degree of empirical support for the proposed framework.

\section{Acknowledgments}

This research was supported by grant No. 274117 from the Academy of Finland, awarded to the third author, and by the Australian Research Council under the Discovery Award (DP150101142), awarded to the second author.

\section{References}

Alexander, P. A. (2018). Information management versus knowledge building: Implications for learning and assessment in higher education. In O. Zlatkin-Troitschanskaia, M. Toepper, H. A. Pant, C. Lautenbach, \& C. Kuhn (Eds.), Assessment of learning outcomes in higher education: Crossnational comparisons and perspectives, 43-56. Cham: Springer International Publishing. https://doi.org/10.1007/978-3-319-74338-7_3

Anderson, C. H. (2007). Perspectives on science learning. In S. K. Abell \& N. G. Lederman (Eds.), Handbook of research on science education. New Jersey: Lawrence Erlbaum Associates.

Bales, R. F. (1950). Interaction process analysis: A method for the study of small groups. Cambridge: Allison-Wesley.

Bales, R. F., \& Slater, P. E. (1955). Role differentiation in small decision-making groups. In T. Parsons \& R. F. Bales (Eds.), Family, socialization and interaction process (pp. 259-306). Illinois: The Free Press.

Belbin, M. (1993). Team roles at work. Oxford: Butterworth-Heinemann.

Benne, K. D., \& Sheats, P. (2007, reprinted). Functional roles of group members. Group Facilitation, 8, 30-35. https://doi.org/10.1111/j.1540-4560.1948.tb01783.x

Benne. K. D., \& Sheats, P. (1948). Functional roles of group members. Journal of Social Issues, 4, 41-49. https://doi.org/10.1111/j.1540-4560.1948.tb01783.x

Cesareni, D., Cacciamani, S., \& Fujita, N. (2016). Role taking and knowledge building in a blended university course. International Journal of Computer-Supported Collaborative Learning, 11(1), 9-39. https://doi.org/10.1007/s11412-015-9224-0

Cheng, B., Wang, M., \& Mercer, N. (2014). Effects of role assignment in concept mapping mediated small group learning. Internet and Higher Education, 23, 27-38.

https://doi.org/10.1016/j.iheduc.2014.06.001 
Chiu, M. M. (2000). Group problem-solving processes: Social interactions and individual actions. Journal for the Theory of Social Behavior, 30(1), 27-49. https://doi.org/10.1111/14685914.00118

Cohen, E. G. (1994). Restructuring the classroom: Conditions for productive small groups. Review of Educational Research, 64(1), 1-35. https://doi.org/10.3102/00346543064001001

De Wever, B., Keer, H. Van, Schellens, T., \& Valcke, M. (2010). Roles as a structuring tool in online discussion groups: The differential impact of different roles on social knowledge construction. Computers in Human Behavior, 26(4), 516-523. https://doi.org/10.1016/j.chb.2009.08.008

De Wever, B., Van Keer, H., Schellens, T., \& Valcke, M. (2009). Structuring asynchronous discussion groups: The impact of role assignment and self-assessment on students' levels of knowledge construction through social negotiation. Journal of Computer Assisted Learning, 25(2), 177 188. https://doi.org/10.1111/j.1365-2729.2008.00292.x.

Driskell, T., Driskell, J. E., Burke, C. S., \& Salas, E. (2017). Team roles: A review and integration. Small Group Research, 48(4), 482-511. https://doi.org/10.1177/1046496417711529

Duschl, R., \& Hamilton, R. (2011). Learning science. In R. E. Mayer \& P. A. Alexander (Eds.), Handbook of research on learning and instruction (pp. 78-107). New York \& London: Routledge.

Forsyth, D. R. (2014). Group dynamics $\left(6^{\text {th }}\right.$ ed.). Belmont: Wadsworth Cengage Learning.

Greeno, J. G. (1998). The situativity of knowing, learning, and research. American Psychologist, 53, 5-26. https://doi.org/10.1037/0003-066X.53.1.5

Greeno, J. G. (2006). Learning in activity. In R. K. Sawyer (Ed.), The Cambridge handbook of the learning sciences (pp. 79-96). New York, NY, US: Cambridge University Press https://doi.org/10.1017/CBO9781139519526.009

Gu, X., Shao, Y., Guo, X., \& Lim, C. P. (2015). Designing a role structure to engage students in computer-supported collaborative learning. Internet and Higher Education, 24, 13-20. 10.1016/j.iheduc.2014.09.002

Hadwin, A. F., Järvelä, S., \& Miller, M. (2018). Self-regulation, co-regulation and shared regulation in collaborative learning environments. In D. H. Schunk, \& J. A. Greene (Eds.). Handbook of selfregulation of learning and performance ( $2^{\text {nd }}$ ed.) (pp. 83-106). New York, NY.

Hare, A. P. (1994). Types of roles in small groups. Small Group Research, 25(3), 433-448. https://doi.org/10.1177/1046496494253005

Heinimäki, O-P., Salo, A-E., \& Vauras, M. (2019). Luonnontieteiden yhteisöllisessä tietokoneavusteisessa oppimisessa omaksuttujen funktionaalisten osallistumisen roolien luokittelun kehittely [Development of a classification for functional participatory roles enacted during computersupported collaborative science learning]. Psykologia, 54(04), 236-254.

Hilpert, J. C., \& Marchand, G. C. (2018). Complex systems research in educational psychology: Aligning Theory and method. Educational Psychologist, 53(3), 185-202. https://doi.org/10.1080/00461520.2018.1469411

Hoadley, C. (2010). Roles, design, and the nature of CSCL. Computers in Human Behavior, 26(4), 551-555. https://doi.org/10.1016/j.chb.2009.08.012

Hogan, K. (1999). Sociocognitive roles in science group discourse. International Journal of Science Education, 21(8), 855-882. https://doi.org/10.1080/095006999290336

Iiskala, T., Volet, S., Lehtinen, E., \& Vauras, M. (2015). Socially Shared Metacognitive Regulation in Asynchronous CSCL in Science: Functions, Evolution and Participation. Frontline Learning Research, 3(1), 78-111. https://doi.org/10.14786/flr.v3i1.159

Järvenoja, H., Järvelä, S., \& Malmberg, J. (In press). Supporting groups' emotion and motivation regulation during collaborative learning. Learning and Instruction. https://doi.org/10.1016/j.learninstruc.2017.11.004

Johnson, D. W., \& Johnson, R. T. (1989). Cooperation and competition: Theory and research. Edina: Interaction Book Company.

Khosa, D. K., \& Volet, S. E. (2013). Promoting effective collaborative case-based learning at university: A metacognitive intervention. Studies in Higher Education, 38, 870-889. http://dx.doi.org/10.1080/03075079.2011.604409

Khosa, D. K., \& Volet, S. E. (2014). Productive group engagement in cognitive activity and metacognitive regulation during collaborative learning: Can it explain differences in students' conceptual 
understanding? Metacognition and Learning, 9, 287-307. https://doi.org/10.1007/s11409-0149117-z

Khosa, D. K., Volet, S. E., \& Bolton, J. R. (2010). An instructional intervention to encourage effective deep collaborative learning in undergraduate veterinary students. Journal of Veterinary Medical Education, 37, 368-375. https://doi.org/10.3138/jvme.37.4.369

Khosa, D., Volet, S. E., \& Bolton, J. (2014). Clinical case-based learning in health sciences: Analysis of collaborative concept mapping processes and reflections. Journal of Veterinary Medical Education, 41, 406-417. https://doi.org/10.3138/jvme.0314-035R1

Kirschner, P., Sweller, J., \& Clark, R. (2006). Why minimal guidance during instruction does not work: An analysis of the failure of constructivist, discovery, problem-based, experiential and inquiry-based teaching. Educational Psychologist, 41, 75-86. https://doi.org/10.1207/s15326985ep4102_1

Landis, J. R., \& Koch, G. G. (1977). The measurement of observer agreement for categorical data. Biometrics, 33, 159-174. DOI:10.2307/2529310

Lehmann-Willenbrock, N., Beck, S. J., \& Kauffeld, S. (2016). Emergent team roles in organizational meetings: Identifying communication patterns via cluster analysis. Communication Studies, 67(1), 37-57. https://doi.org/10.1080/10510974.2015.1074087

Ludvigsen, S., Lund, A., Rasmussen, I., \& Säljö, R. (2011). Introduction. In S. Ludvigsen, A. Lund., I. Rasmussen, \& R. Säljö (Eds.), Learning across sites: New tools, infrastructures and practices (pp. 1-13). New York: Routledge.

Maloney, J. (2007). Children's roles and use of evidence in science: An analysis of decision-making in small groups. British Educational Research Journal, 33(3), 371-401. https://doi.org/10.1080/01411920701243636

Marcos-García, J. A., Martínez-Monés, A., \& Dimitriadis, Y. (2015). DESPRO: A method based on roles to provide collaboration analysis support adapted to the participants in CSCL situations. Computers and Education, 82, 335-353. https://doi.org/10.1016/j.compedu.2014.10.027

Morris, R., Hadwin, A. F., Gress, C. L. Z., Miller, M., Fior, M., Church, H., \& Winne, P. H. (2010). Designing roles, scripts, and prompts to support CSCL in gStudy. Computers in Human Behavior, 26(5), 815-824. https://doi.org/10.1016/j.chb.2008.12.001

Moxnes, P. (1999). Understanding roles: A psychodynamic model for role differentiation in groups. Group Dynamics: Theory, Research, and Practice, 3(2), 99-113. https://doi.org/10.1037/10892699.3.2.99

Nolen, S. B., Horn, I. S., \& Ward, C. J. (2015). Situating motivation. Educational Psychologist, 50(3), 234-247. https://doi.org/10.1080/00461520.2015.1075399.

Oliveira, A. W., Boz, U., Broadwell, G. A., \& Sadler, T. D. (2014). Student leadership in small group science inquiry. Research in Science and Technological Education, 32(3), 281-297. https://doi.org/10.1080/02635143.2014.942621

Pietarinen, T., Vauras, M., Laakkonen, E., Kinnunen, R., \& Volet, S. (2019). High school students' perceptions of affect and collaboration during virtual science inquiry learning. Journal of Computer Assisted Learning, 35, 334-348. https://doi.org/10.1111/jcal.12334

Pino-Pasternak, D., \& Volet, S. (2018). Evolution of pre-service teachers' attitudes towards learning science during an introductory science unit. International Journal of Science Education, 40(12), 1520-1541. https://doi.org/10.1080/09500693.2018.1486521

Pozzi, F. (2011). The impact of scripted roles on online collaborative learning processes. International Journal of Computer-Supported Collaborative Learning, 6(3), 471-484. DOI: 10.1007/s11412011-9108-x

Salazar, A. J. (1996). An analysis of the development and evolution of roles in the small group. Small Group Research, 27(4), 475-503. https://doi.org/10.1177/1046496496274001

Sarmiento, J. W., \& Shumar, W. (2010). Boundaries and roles: Positioning and social location in the Virtual Math Teams (VMT) online community. Computers in Human Behavior, 26(4), 524 532. https://doi.org/10.1016/j.chb.2009.08.009

Schellens, T., Van Keer, H., De Wever, B., \& Valcke, M. (2007). Scripting by assigning roles: Does it improve knowledge construction in asynchronous discussion groups? International Journal of 
Computer-Supported Collaborative Learning, 2, 225-246. https://doi.org/10.1007/s11412-0079016-2

Slavin, R. (1996). Research on cooperative learning and achievement: What we know, what we need to know. Contemporary Educational Psychology, 69(1), 43-69.

https://doi.org/http://dx.doi.org/10.1006/ceps.1996.0004

Stewart, G. L., Fulmer, I. S., \& Barrick, M. R. (2005). An exploration of member roles as a multilevel linking mechanism for individual traits and team outcomes. Personnel Psychology, 58, 343365. https://doi.org/10.1111/j.1744-6570.2005.00480.x

Strijbos, J. W., \& De Laat, M. F. (2010). Developing the role concept for computer-supported collaborative learning: An explorative synthesis. Computers in Human Behavior, 26(4), 495-505. https://doi.org/10.1016/j.chb.2009.08.014

Strijbos, J. W., \& Weinberger, A. (2010). Emerging and scripted roles in computer-supported collaborative learning. Computers in Human Behavior, 26(4), 491-494. https://doi.org/10.1016/j.chb.2009.08.006

Strijbos, J.-W., Martens, R. L., Jochems, W. M. G., \& Broers, N. J. (2004). The effect of functional roles on group efficiency: Using multilevel modeling and content analysis to investigate computer-supported collaboration in small groups. Small Group Research, 35(2), 195-229. https://doi.org/10.1177/1046496403260843

Turner, J. C., \& Nolen, S. B. (2015). Introduction: The relevance of the situative perspective in educational psychology. Educational Psychologist, 50(3), 167-172. https://doi.org/10.1080/00461520.2015.1075404

Ucan, S., \& Webb, M. (2015). Social regulation of learning during collaborative inquiry learning in science: How does it emerge and what are its functions? International Journal of Science Education, 37(15), 2503-2532. https://doi.org/10.1080/09500693.2015.1083634

Vauras, M., Telenius, M., Yli-Panula, E., Iiskala, T., Pietarinen, T., \& Kinnunen, R. (2017). Virtuaalinen tutkimusmatka luonnontieteelliseen osaamiseen [Virtual exploration into learning science]. In H. Savolainen, R. Vilkko, \& L. Vähäkylä (Eds.), Oppimisen tulevaisuus [Future of learning], 24-35. Porvoo: Gaudeamus.

Vauras, M., Volet, S., \& Nolen, S. (2019). Supporting motivation in collaborative learning: Challenges in the face of an uncertain future. In E. Gonida \& M. Lemos (Eds.), Motivation in education at a time of global change: Theory, research, and implications for practice (pp. 187-203). New York: Emerald.

Volet, S., \& Summers, M. (2013). Interpersonal regulation in collaborative learning activities: Reflections on emerging research methodologies. In S. Volet \& M. Vauras (Eds.), Interpersonal regulation of learning and motivation: Methodological advances (pp. 204-220). London \& New York: Routledge.

Volet, S., Jones, C., \& Vauras, M. (2019). Preservice primary teachers' science learning: Effects of within-group diversity of attitudes on productive engagement. Learning and Individual Differences, 73, 79-91. https://doi.org/10.1016/j.lindif.2019.05.002

Volet, S., Summers, M., \& Thurman, J. (2009). High-level co-regulation in collaborative learning: How does it emerge and how is it sustained? Learning and Instruction, 19(2), 128-143. https://doi.org/10.1016/j.learninstruc.2008.03.001

Volet, S., Vauras, M., Salo, A. E., \& Khosa, D. (2017). Individual contributions in student-led collaborative learning: Insights from two analytical approaches to explain the quality of group outcome. Learning and Individual Differences, 53, 79-92. https://doi.org/10.1016/j.lindif.2016.11.006

Webb, M. (2008). Learning in small groups. In T. L. Good (Ed.), 21st century education: A reference handbook (pp. 203-211). Thousand Oaks: Sage Publications. 